\title{
Pro- and Antiapoptotic Markers in Upper Tract Urothelial Carcinoma Associated with Balkan Endemic Nephropathy
}

Ljubinka Jankovic-Velickovic, ${ }^{1}$ Slavica Stojnev, ${ }^{1}$ Ana Ristic-Petrovic, ${ }^{1}$ Zana Dolicanin, ${ }^{1}$ Takanori Hattori, ${ }^{2}$ Kenichi Mukaisho, ${ }^{2}$ Mariola Stojanovic, ${ }^{3}$ and Vladisav Stefanovic ${ }^{4}$

${ }^{1}$ Institute of Pathology, Faculty of Medicine, University of Nis, 18000 Nis, Serbia

${ }^{2}$ Department of Pathology, Shiga University of Medical Science, Seta Tsukinowa-cho, Otsu, Shiga 520-2121, Japan

${ }^{3}$ Public Health Institute, Nis, Serbia

${ }^{4}$ Institute of Nephrology, Faculty of Medicine, University of Nis, Boulevard Dr Zoran Djindjic 81, 18000 Nis, Serbia

Received 4 July 2011; Accepted 6 September 2011

Academic Editor: Anthony Atala

The role of aristolochic acid in the etiology of Balkan endemic nephropathy (BEN) and associated upper-tract urothelial carcinoma (UTUC) has been recently confirmed. The aim of this study was to determine apoptosis-related marker(s) specific for BEN-associated UTUC. Present investigation included 105 patients with UTUC, 44 from BEN region and 61 control tumors. Altered expression of Survivin was more often present in BEN UTUC with high grade and solid growth $(P<0.005$; $P<0.05)$ than in control tumors. Significantly lower expression of proapoptotic marker Bax was found in BEN tumors with high grade, high stage, necrosis, and without metaplastic change $(P<0.05 ; 0.05 ; 0.05 ; 0.05)$ compared to control tumors with the same features. Group (BENrelated/control), stage, growth pattern, and caspase 3 activity were significantly associated with the expression of $\operatorname{Bax}(P=0.002,0.034,0.047,0.028$, resp., $)$. This investigation identifies $\mathrm{Bax}$ as specific marker of BEN-associated UTUC. Decrease of pro-apoptotic protein Bax together with alteration of Survivin may be indicative for specific disturbances of intrinsic apoptotic pathway in UTUC arising in endemic areas.

KEYWORDS: Balkan endemic nephropathy, upper tract urothelial carcinoma, apoptosis, Survivin, Bcl-2, Bax, Fas, Caspase 3 


\section{INTRODUCTION}

Balkan endemic nephropathy (BEN) is a chronic tubulointerstitial disease with insidious onset and slow progression to terminal renal failure. BEN is geographically confined to several rural regions of the Balkans along the Danube river [1]. In Serbia BEN was described in 1957, and in the last fifty years much was done to advance the understanding of this disease [2]. BEN is an environmental disease, the result of interplay of environmental and genetic factors [3, 4]. Several investigators suggested that the disease could result from prolonged exposure to a multitude of environmental toxicants, such as herbs containing aristolochic acid (AA) [5, 6], mycotoxins [7], and organic compounds leached from coal deposits [8]. In addition to renal disease, an increased number of upper tract urothelial carcinoma (UTUC) have been observed in the foci of BEN $[9,10]$. Carcinomas may occur alone or in combination with BEN. Their incidence increases with age at the time of diagnosis and with a longer survival and is higher in females [1,10]. The molecular mechanism of AA-induced carcinogenesis demonstrated a strong association between DNA adduct formation, mutation pattern, and tumor development $[11,12]$. Our recent investigation detected p53 pathway as the specific cell cycle marker involved in BEN-related UTUC [13].

Similar to other neoplasms, urothelial cancer initiates and progresses from genetic and epigenetic events affecting the complex, but delicates molecular interplay of factors that drive the cell to survive and proliferate or to enter the spiral of programmed cell death. To date, limited number of studies investigated apoptosis-related markers in patients with UTUC, probably due to the relative rarity of urothelial cancers of renal pelvis and ureter. Urothelial cancer may resist programmed cell death with altered expression of both proapoptotic and antiapoptotic proteins $[14,15]$.

The aims of this study were to evaluate and correlate the expression of apoptotic markers-Survivin, Bcl-2, Bax, Fas, and caspase 3-with pathological characteristics of UTUC in BEN and control population and to determine the apoptotic marker(s) which is specific indicator of BEN-related UTUC.

\section{PATIENTS AND METHODS}

\subsection{Patients Population}

We studied 105 consecutive patients with UTUC who had undergone the open type of nephroureterectomy with removal of bladder cuff as part of the nephroureterectomy procedure. Extended lymphadenectomy was not routinely performed. All cases of UTUC were diagnosed at the Institute of Pathology, Faculty of Medicine, Nis Serbia. The analysis included 73 transitional cell carcinomas with pelvic localization and 32 with, ureteral. Patients were divided in two groups: 44 patients were from endemic settlements, the villages along the South Morava River basin (BEN tumors), and 61 control subjects, residents of rural and city areas free of BEN.

\subsection{Histologic Analysis}

The histological sections were processed from tissue fixed in $10 \%$ formalin by standard techniques and stained with haematoxylin and eosin (H\&E). H\&E-stained slides were used to assess histological grade (low and high grade) [16], pathologic stage (pT) [17], growth of tumor (papillary/solid), lymphovascular invasion (LVI), and the presence of necrosis and metaplastic changes (squamous or glandular) within the tumor. The authors compared low-stage nonmuscle invasive tumors (pTa-pT1) and high-stage muscle invasive (pT2-pT4) tumors [18]. The presence of tumor necrosis was evaluated based on microscopic examination of tumor. According to the WHO criteria for the diagnosis of histological variants of urothelial cancer, squamous differentiation was defined as the presence of intercellular bridges or keratinization [16]. The conventional criteria for squamous metaplastic change in UTUC include abundant eosinophilic cytoplasm and large oval nuclei with an open chromatin pattern and prominent nucleoli. Glandular 
differentiation was defined as the presence of true glandular spaces and gland-like lumina within tumor cell nests.

\subsection{Immunohistochemistry and Scoring}

Tumors were analyzed using the mouse monoclonal antibodies against Bcl-2 (Clone 124, M 0887/Dako), Survivin (FL-142: sc-10811/Santa Cruz Biotechnology), Bax (Code A 3533/Dako), Fas (C-20: sc715/Santa Cruz Biotechnology), and caspase 3 cleaved (ACR 229 A, B, C/Biocare Medical) at dilution of $1: 50,1: 500,1: 1000,1: 100,1: 200$, respectively, and a standard avidin-biotin immunoperoxidase complexes detection system, according to the manufacturer's protocol (Dako LSAB2R system-HRP). Before quantifying the immunohistochemical results, the technique quality was assessed, and those areas with greater positivity were selected, avoiding peripheral area measurement, necrosis, or artifact. Slides were reviewed independently by three investigators (LJV, SS, ARP). Interobserver discrepancies were resolved using a double-headed microscope. Nuclear expression was recorded for Survivin, membranous and cytoplasmic for Fas [19], and cytoplasmic for Bax, Bcl-2, and caspase 3.

Immunohistochemical reaction was scored as follows: negative if $\leq 10 \%$ of cells were stained and positive if $\geq 10 \%$ were stained. Cytoplasmic staining intensity was scored using a scale of 0 to 3 ( 0 , no staining; 1 , weak; 2, moderate; 3 , intense). All markers were placed in one of two categories, altered or not altered (normal). Nuclear Survivin immunoreactivity was considered altered when samples demonstrated at least $10 \%$ nuclear reactivity [20]. Bcl-2, Bax, and Fas immunoreactivity was considered altered when samples demonstrated positivity in $>10 \%$ of tumor cells with an intensity of 2 or 3 . Cleaved caspase 3 index was calculated as number of positive cells $\times 100$ per total number of cells in ten random high-power fields (x400) in each tumor. This index was established by counting at least 2000 cells in fields distant from necrotic areas $[21,22]$.

\subsection{Statistical Analysis}

For purposes of analysis, pathological tumor stage (low versus high), grade (low versus high), growth pattern (papillary versus solid), LVI (yes versus no), and clinical parameters-sex (M versus F), localization (pelvis versus ureter) - were evaluated as dichotomized variables. The Fisher's exact test and the $\chi^{2}$ test were used to estimate the expression of Survivin, Bcl-2, Bax, and Fas in regard to pathological parameters (stage, grade, growth, lymphovascular invasion, necrosis, metaplastic differentiation) of tumors and Mann-Whitney $U$ test in evaluation of caspase 3 index with investigated parameters. Spearman's non-parametric coefficients and Pearson's correlation coefficients were calculated to estimate correlations between pathological characteristics and expression of apoptotic markers. In order to determine the influence of each variable on expression of apoptotic biomarkers, a multivariate binary logistic regression was performed. Odds ratios (OR) were estimated using the 95\% confidence interval (CI), as well as linear regression model for continuous variable—cleaved caspase 3 index. The result was considered statistically significant if $P<0.05$. All analyses were performed with the SPSS statistical package (SPSS version 10.0 for Windows).

\section{RESULTS}

\subsection{Clinical Features in UUC}

The age in 105 patients with UTUC ranged from 32 to 87 years, with a mean age of $64.5 \pm 8.8$ years for tumors in BEN regions and $64.2 \pm 11$ years for control tumors. There were 22 male (50\%) and 22 female $(50 \%)$ patients in BEN-associated UTUC group with ratio $\mathrm{M}: \mathrm{F}=1: 1$, while in the control group there were 37 men $(61 \%)$ and 24 women $(39 \%)$, with ratio $\mathrm{M}: \mathrm{F}=1.5: 1$. Tumor localization was more frequent 


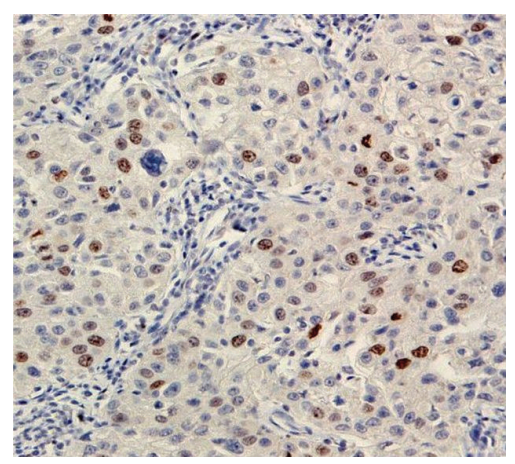

(a)

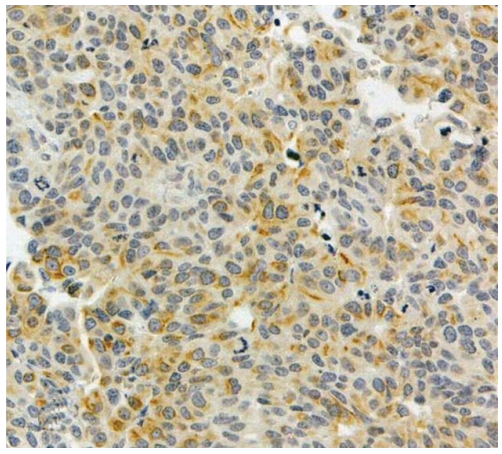

(d)

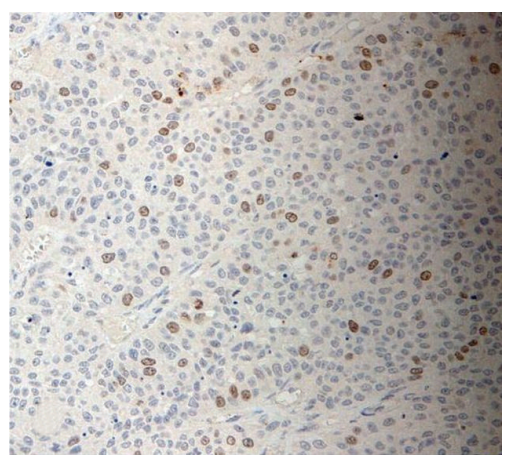

(b)

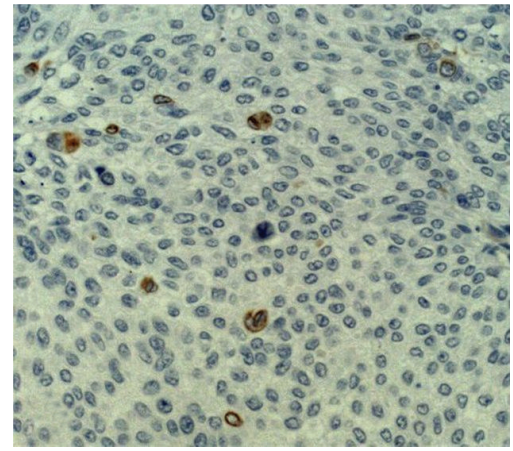

(e)

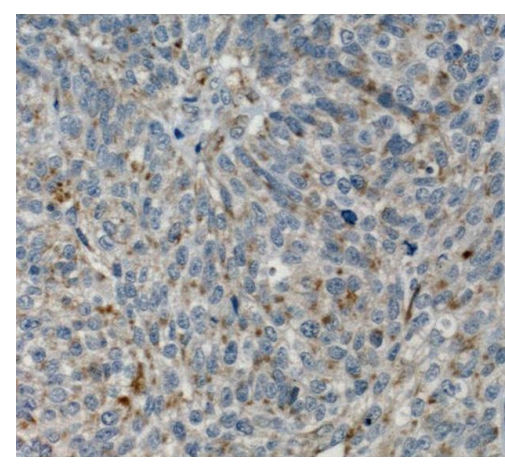

(c)

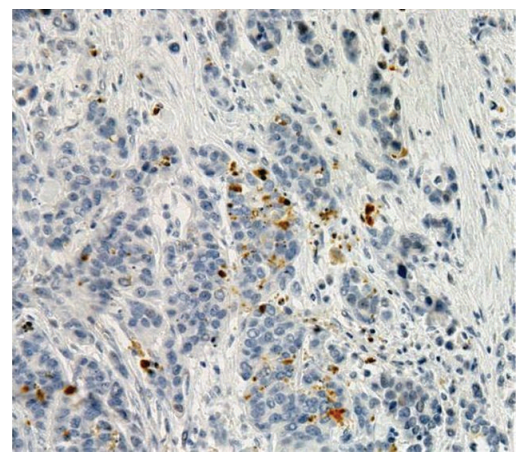

(f)

FIGURE 1: The representative immunohistochemical staining of apoptotic markers in BEN-associated urothelial carcinoma, with strong nuclear Survivin activity in high grade (a) and tumors with solid growth (b), diffuse Bax cytoplasm expression (c), membranous Fas staining in nonmetaplastic BEN-related tumors (d). Rarely Bcl-2 positive tumor cells (e). Caspase 3 expression in a high-grade tumor (f) (original magnification: $\mathrm{x} 400)$.

on the left side in both BEN and control UTUC, however, without statistical difference between these two groups (27/17 versus 37/24).

\subsection{Immunohistochemical Evaluation of Apoptosis-Related Biomarkers and Association with Pathological Characteristics in BEN and Control UTUC}

The immunohistochemical staining of Survivin, Bcl-2, Bax, and Fas was detected in 81 (77.1\%), 34 (32.4\%), 79 (75.2\%), and 73 (69.5\%) UTUC, respectively. Apoptotic markers-Survivin, Bcl-2, Bax, and Fas-were altered in 55 (52.4\%), 16 (15.2\%), 61 (58.1\%), 45 (42.9\%) UTUC, respectively. The mean caspase 3 labeling index was $2.5 \pm 7.4 \%$ (SD). Tables 1 and 2 displays relationships between conventional pathological parameters and immunohistochemical staining of Survivin, Bcl-2, Bax, Fas, and caspase 3 in BEN and control UTUC. Nuclear immunostaining of Survivin was significantly higher in BEN tumors with high grade and solid growth than in those of the control group $\left(\chi^{2}=4.96, P<0.005 ; \chi^{2}=4.0, P<0.05\right.$, resp.) (Figures 1(a) and 1(b) ). Immunostaining of the proapoptotic marker Bax was lower in BEN tumors (Figure 1(c)) with the high grade, high stage, with the presence of necrosis, and without metaplastic differentiation $\left(\chi^{2}=5.73, P<0.05 ; \chi^{2}=4.84, P<0.05 ; \chi^{2}=4.13, P<0.05 ; \chi^{2}=3.85, P<0.05\right.$, resp.) than in control tumors with the same morphological characteristics. Moreover, BEN UTUC without metaplastic change had higher expression of Fas (Figure 1(d) ) than control tumors $\left(\chi^{2}=5.38, P<0.05\right)$. 
TABLE 1: Association of antiapoptotic biomarkers expression with pathological characteristics of UTUC.

\begin{tabular}{|c|c|c|c|c|c|}
\hline \multirow{2}{*}{ UUC } & \multirow{2}{*}{$N$} & \multicolumn{4}{|c|}{ Altered expression of biomarker } \\
\hline & & Survivin & $P<$ & $\mathrm{Bcl}-2$ & $P<$ \\
\hline Low grade & & & N.S. & & N.S. \\
\hline BEN & 16 & 5 & & 3 & \\
\hline Control & 25 & 12 & & 4 & \\
\hline High grade & & & 0.05 & & N.S. \\
\hline BEN & 28 & 21 & & 4 & \\
\hline Control & 36 & 17 & & 5 & \\
\hline Low stage & & & N.S. & & N.S. \\
\hline BEN & 17 & 10 & & 2 & \\
\hline Control & 19 & 8 & & 4 & \\
\hline High stage & & & N.S. & & N.S. \\
\hline BEN & 27 & 16 & & 5 & \\
\hline Control & 42 & 21 & & 5 & \\
\hline Papillary growth & & & N.S. & & N.S. \\
\hline BEN & 12 & 4 & & 2 & \\
\hline Control & 27 & 14 & & 5 & \\
\hline Solid growth & & & 0.05 & & N.S. \\
\hline BEN & 32 & 22 & & 5 & \\
\hline Control & 34 & 15 & & 4 & \\
\hline LV invasion: yes & & & N.S. & & N.S. \\
\hline BEN & 10 & 8 & & 1 & \\
\hline Control & 20 & 10 & & 2 & \\
\hline Necrosis: yes & & & N.S. & & N.S. \\
\hline BEN & 19 & 12 & & 4 & \\
\hline Control & 25 & 12 & & 2 & \\
\hline Nonmetaplastic & & & N.S. & & N.S. \\
\hline BEN & 34 & 18 & & 4 & \\
\hline Control & 48 & 22 & & 5 & \\
\hline Metaplastic & & & N.S. & & N.S. \\
\hline BEN & 10 & 8 & & 3 & \\
\hline Control & 13 & 7 & & 3 & \\
\hline
\end{tabular}

$\chi^{2}$ test was performed.

N.S.: no significance.

The expression of Bcl-2 and cleaved caspase 3 were not significantly associated with the phenotypic characteristics of BEN-associated UTUC (Figures 1(e) and 1(f) ) and control UTUC.

\subsection{Comparison of Apoptosis-Related Biomarkers in BEN and Control UTUC}

Comparing apoptosis-related biomarkers and group, the significant difference in Bax expression was detected (Table 3). BEN tumors had less frequent alteration of Bax than control tumors (20/24 (45.5\%) 
TABLE 2: Association of proapoptotic biomarkers expression with pathological characteristics of UTUC.

\begin{tabular}{|c|c|c|c|c|c|c|c|}
\hline \multirow{2}{*}{ UUC } & \multirow{2}{*}{$N$} & \multicolumn{6}{|c|}{ Altered expression of biomarker } \\
\hline & & Bax & $P<$ & Fas & $P<$ & Casp3 index* & $P<$ \\
\hline Low grade & & & N.S. & & N.S. & & N.S \\
\hline BEN & 16 & 9 & & 7 & & $6.7 \pm 15.8$ & \\
\hline Control & 25 & 16 & & 8 & & $2 \pm 5.3$ & \\
\hline High grade & & & 0.05 & & N.S. & & N.S \\
\hline BEN & 28 & 11 & & 16 & & $1.7 \pm 2.7$ & \\
\hline Control & 36 & 25 & & 14 & & $1.7 \pm 4.6$ & \\
\hline Low stage & & & N.S. & & N.S. & & N.S \\
\hline BEN & 17 & 10 & & 9 & & $2.9 \pm 7.5$ & \\
\hline Control & 19 & 14 & & 7 & & $2.6 \pm 6.7$ & \\
\hline High stage & & & 0.05 & & N.S. & & N.S \\
\hline BEN & 27 & 10 & & 14 & & $3.9 \pm 11.2$ & \\
\hline Control & 42 & 27 & & 15 & & $1.5 \pm 3.9$ & \\
\hline Papillary growth & & & N.S. & & N.S. & & N.S \\
\hline BEN & 12 & 4 & & 3 & & $4.2 \pm 8.8$ & \\
\hline Control & 27 & 18 & & 8 & & $3.2 \pm 7.1$ & \\
\hline Solid growth & & & N.S. & & N.S. & & N.S \\
\hline BEN & 32 & 16 & & 20 & & $3.2 \pm 10.4$ & \\
\hline Control & 34 & 23 & & 14 & & $0.8 \pm 1$ & \\
\hline LV invasion: yes & & & N.S. & & N.S. & & N.S \\
\hline BEN & 10 & 4 & & 6 & & $7 \pm 17.9$ & \\
\hline Control & 20 & 15 & & 7 & & $1 \pm 1.3$ & \\
\hline Necrosis: yes & & & 0.05 & & N.S. & & N.S \\
\hline BEN & 19 & 7 & & 10 & & $1.9 \pm 2.8$ & \\
\hline Control & 25 & 17 & & 11 & & $1 \pm 1$ & \\
\hline Nonmetaplastic & & & 0.05 & & 0.05 & & N.S \\
\hline BEN & 34 & 16 & & 17 & & $3.6 \pm 11.1$ & \\
\hline Control & 48 & 33 & & 12 & & $1.7 \pm 4.3$ & \\
\hline Metaplastic & & & N.S. & & N.S. & & \\
\hline BEN & 10 & 4 & & 6 & & $3.2 \pm 4$ & \\
\hline Control & 13 & 8 & & 10 & & $2.6 \pm 6.8$ & \\
\hline
\end{tabular}

$\chi^{2}$ test was performed.

*Mann Whitney $U$ test was performed.

N.S.: no significance.

versus $\left.41 / 20(67.2 \%), \chi^{2}=4.92, P<0.05\right)$. In contrast to this marker, the expression of Survivin, Bcl-2, Fas, and caspase 3 was not significantly associated with the groups (Table 3 ).

A possible correlation between Survivin, Bcl-2, Bax, Fas, and caspase 3 activity and standard pathological features and group was also investigated. Spearman's coefficient of correlation showed that Survivin correlates with the Bcl-2 and Fas (correlation coefficient $\rho=0.192,0.248, P=0.050,0.011$ ), Bcl2 with the expression of Bax, and Fas (correlation coefficient $\rho=0.199,0.275, P=0.042,0.004$, resp.), 
TABLE 3: Expression of apoptosis-related markers in UTUC associated with BEN and in control UTUC.

\begin{tabular}{lccc}
\hline Molecular marker & BEN $(N=44)$ & Control $(N=61)$ & $P<$ \\
\hline Survivin & & & Expression $N(\%)$ \\
$\quad$ Not altered & $18(40.9)$ & $32(52.5)$ & \\
$\quad$ Altered & $26(59.1)$ & $29(47.5)$ & N.S. \\
\hline Bcl-2 & $37(84.1)$ & $52(85.2)$ & \\
$\quad$ Not altered & $7(15.9)$ & $9(14.8)$ & 0.05 \\
$\quad$ Altered & & & \\
\hline Bax & $24(54.5)$ & $20(32.8)$ & N.S. \\
$\quad$ Not altered & $20(45.5)$ & $41(67.2)$ & \\
$\quad$ Altered & & $39(63.9)$ & N.S. \\
\hline Fas & $21(47.7)$ & $22(36.1)$ & \\
$\quad$ Not altered & $23(52.3)$ & $1.9 \pm 4.9$ & \\
$\quad$ Altered & & & \\
\hline Caspase 3* & & & \\
$\quad X \pm$ SD & $3.5 \pm 9.9$ & & \\
\hline$\chi^{2}$ test was performed & & & \\
N.Sann Whitney $U$ test was performed & & & \\
\end{tabular}

Bax correlates with the group (correlation coefficient $\rho=0.218, P=0.026$ ), and Fas activity with the localization, growth, and metaplastic change (correlation coefficient $\rho=0.263,0.228,0.286, P=0.007$, $0.020,0.003$, resp.). Index of caspase 3 activity is in correlation with the expression of Survivin, Bcl-2, Bax, and Fas (Pearson's correlation coefficient $r=0.192,0.522,0.200,0.280 ; P=0.050,0.0001,0.040,0.004$, resp.).

In addition, multistep logistic regression model which included investigated apoptotic markers (Survivin, Bcl-2, Bax, and Fas), group, pathological characteristics, gender, and localization, showed that the proapoptotic marker Fas had prominent influence to the expression of Survivin (Wald $=5.841 P=$ 0.016 ), caspase 3 index to the expression of $\mathrm{Bcl}-2$ (Wald $=10.736 P=0.001$ ) and group, stage, growth and caspase 3 index had prominent influence to expression of Bax (Wald $=9.919 P=0.002$; Wald $=$ 4.484 $P=0.034$; Wald $=3.940 P=0.047$; Wald $=4.841 P=0.028$ ), while localization, metaplastic change in UTUC, and caspase 3 index were significantly associated with the proapoptotic marker Fas (Wald $=6.102 P=0.013$; Wald $=4.138 P=0.042$; Wald $=5.622 P=0.018$, Table 4). In linear regression model which detected influence of investigated parameters to caspase 3 activity, we found that differentiation of UTUC and Bcl-2 had significant influence $(t=-2.243 P=0.027 ; t=5.665 P=0.0001)$. Between investigated apoptotic markers, only Bax was specific indicator of group. UTUC from BEN region was associated with reduction of this proapoptotic marker.

\section{DISCUSSION}

Approximately 5\% of urothelial tumors arise in the upper urinary tract [23]. Although both derived from urothelial cells, recent studies established certain discrepancies between transitional cell carcinoma (TCC) of upper and lower urothelium in relation to the mechanisms of carcinogenesis, biological behavior, and 
TABLE 4: Multivariate logistic regression and linear regression analysis of all UTUC.

\begin{tabular}{|c|c|c|c|c|c|c|c|c|c|}
\hline \multirow{2}{*}{$\begin{array}{l}\text { Logistic } \\
\text { regresion } \\
\text { Model } \\
\text { sig. }\end{array}$} & \multirow[t]{2}{*}{$\begin{array}{l}\text { Dependent } \\
\text { variable }\end{array}$} & \multirow[t]{2}{*}{ Predictor } & \multirow[t]{2}{*}{$B$} & \multirow[t]{2}{*}{ S.E. } & \multirow[t]{2}{*}{ Wald } & \multirow[t]{2}{*}{ Sig. } & \multirow[t]{2}{*}{$\operatorname{Exp}(B)$} & \multicolumn{2}{|c|}{$\begin{array}{l}95.0 \% \text { C.I. } \\
\text { for } \operatorname{EXP}(B)\end{array}$} \\
\hline & & & & & & & & Lower & Upper \\
\hline \multirow[t]{2}{*}{0.014} & Survivin & Fas & -0.996 & 0.412 & 5.841 & 0.016 & 0.369 & 0.165 & 0.828 \\
\hline & & Constant & 0.659 & 0.318 & 4.296 & 0.038 & 1.933 & & \\
\hline \multirow[t]{2}{*}{0.0001} & Bcl-2 & Caspase 3 & 0.362 & 0.111 & 10.736 & 0.001 & 1.437 & 1.157 & 1.784 \\
\hline & & Constant & -2.667 & 0.421 & 40.215 & 0.000 & 0.069 & & \\
\hline \multirow[t]{5}{*}{0.0001} & Bax & Group & 1.542 & 0.490 & 9.919 & 0.002 & 4.673 & 1.790 & 12.199 \\
\hline & & Stage & 1.125 & 0.531 & 4.484 & 0.034 & 3.080 & 1.087 & 8.723 \\
\hline & & Growth & -1.031 & 0.519 & 3.940 & 0.047 & 0.357 & 0.129 & 0.987 \\
\hline & & Caspase 3 & 0.326 & 0.148 & 4.841 & 0.028 & 1.385 & 1.036 & 1.851 \\
\hline & & Constant & -0.945 & 0.445 & 4.500 & 0.034 & 0.389 & & \\
\hline \multirow[t]{4}{*}{0.0001} & Fas & Pelvis/Ureter & -1.312 & 0.531 & 6.102 & 0.013 & 0.269 & 0.095 & 0.763 \\
\hline & & Metaplastic & -1.215 & 0.597 & 4.138 & 0.042 & 0.297 & 0.092 & 0.957 \\
\hline & & Caspase 3 & 0.318 & 0.134 & 5.622 & 0.018 & 1.374 & 1.057 & 1.787 \\
\hline & & Constant & 1.793 & 0.722 & 6.160 & 0.013 & 6.008 & & \\
\hline $\begin{array}{l}\text { linear } \\
\text { regresion } \\
\text { model }\end{array}$ & $\begin{array}{l}\text { Dependent } \\
\text { variable }\end{array}$ & Predictor & $B$ & S.E. & \multicolumn{3}{|c|}{ Standardized coefficient beta } & $t$ & Sig. \\
\hline \multirow{3}{*}{$\begin{array}{l}\text { F } 12.542 \\
\text { sig. } 0.0001\end{array}$} & Caspase 3 & Differentiation & -2.970 & 1.324 & \multicolumn{3}{|c|}{-0.196} & -2.243 & 0.027 \\
\hline & & Bcl-2 & 9.967 & 1.759 & \multicolumn{3}{|c|}{.0486} & 5.665 & 0.000 \\
\hline & & Constant & -8.376 & 3.075 & & & & -2.724 & 0.008 \\
\hline
\end{tabular}

natural history, since, as a whole, UTUC is more invasive and less differentiated than bladder cancer [24, 25].

In regions associated with $\mathrm{BEN}$, which is today considered an entity of aristolochic acid nephropathy, a worldwide disease [26, 27], UTUC, is up to 100 times more frequent than in nonendemic areas [1]. The comparative study between patients from endemic and nonendemic areas, which included tumor grade, stage, pattern of invasion, growth pattern, lymphovascular invasion, necrosis, and metaplastic changes of UTUC, concluded that growth pattern discriminated these groups of tumors [28]. Further studies implied that the genetic aberrations and molecular pathways included in cancer evolution are also different [11, 13, 29].

Urothelial cancer may resist programmed cell death with altered expression of both antiapoptotic and proapoptotic proteins $[14,15]$. Survivin, a unique member of the inhibitor of apoptosis proteins (IAP) family, is highly expressed during normal tissue development but is absent in most terminally differentiated cells of adult tissues [30]. Survivin becomes prominently reexpressed in variety of cancers [25, 31]. Its overexpression inhibits extrinsic and intrinsic pathways of apoptosis in tumor cells $[15,32]$ and accelerates their mitotic activity [33]. In patients with UTUC, Shariat et al. recognized positive expression of Survivin in $12.7 \%$ of samples, a granular pattern being apparent within the cytoplasm of tumor cells [34]. In this research, we analysed the nuclear Survivin staining, according to the conclusions of recently published studies related to TCC $[20,35]$. We found that $59,1 \%$ of analyzed BEN-associated carcinomas had altered Survivin expression in contrast to $47,5 \%$ immunopositivity in control tumors. However, this difference was not statistically significant. 
In addition, present study demonstrated that Survivin expression was significantly higher in BEN tumors with high grade and solid growth than in control tumors with the same morphological features. Although some authors suggested that Survivin expression did not correlate with clinicopathologic findings in UTUC [36, 37], recent studies of bladder cancer demonstrated that nuclear positive staining correlated strongly with increased grade, stage, and the probability of tumor recurrence [35, 38]. In terms of clinical application, Survivin is regarded one of the most promising prognostic biomarkers for TCC [34].

Another famous antiapoptotic protein, Bcl-2, prevents Bax/Bak interaction, subsequent cytochrome $\mathrm{c}$ release, and caspase activation [39]. Aberrant Bcl-2 staining expressed significant association with tumor grade and tumor invasiveness in the TCC of the bladder [37, 40]. In previous investigations of UTUC, Bcl-2 only significantly correlated with tumor stage [41]. Nevertheless, our results did not reveal any significant association of altered Bcl-2 expression and pathological features of the investigated tumors.

Within the intrinsic apoptotic pathway, in response to proapoptotic stimuli, Bax protein effects the permeabilization of the outer mitochondrial membrane, allowing cytochrome c to escape into the cytosol where it can induce caspase activation and cell death [42]. Our study demonstrated that Bax immunopositivity was significantly associated with the tumor stage, which is in agreement with recently published data related to bladder cancer [40]. Altered expression of Bax was significantly more frequent in the advanced stage tumors. Moreover, Bax expression correlated with caspase 3 index, supporting a proapoptotic role of this protein. Regression analysis, which included all investigated apoptotic markers, group, pathological characteristics, gender, and localization, detected Bax as the specific indicator of UTUC arising in BEN regions. BEN-related UTUC was significantly associated with reduced immunopositivity of Bax compared to control tumors. Bax aberrant staining was less frequent in BEN tumors with high grade, high stage, with necrosis, or without metaplastic change than in control tumors with the same morphological characteristics, thus, implying the decreased proapoptotic activity in tumors arising in endemic regions.

Investigation of Fas receptor expression also showed significant differences between BEN and control tumors with designated features. Aberrant Fas expression was observed in 52.3\% of BEN UTUC and $36.1 \%$ control tumors but without statistically significant difference between these two groups. Although Fas (CD95/Apo1) represents a typical death receptor from tumor necrosis factor superfamily [43] and is located in the cell membrane, Fas immunoreactivity demonstrated predominantly cytoplasmic staining pattern, without clear membranous expression. BEN tumors had significantly higher diffuse cytoplasmic expression of Fas receptor which was detected in nonmetaplastic BEN-associated UTUC. Regression analysis detected Fas as the specific indicator of localization and metaplastic change in UTUC. BEN-related UTUC with localization in ureter was significantly associated with altered Fas expression. Interestingly, recent data suggest that the expression of Fas receptor does not necessarily predict susceptibility to apoptosis and may not correlate with its biological function [44]. In fact, the retention of Fas protein within the cytoplasm may represent a mechanism by which malignant cells evade Fas-mediated apoptosis [19].

Two major apoptotic pathways, a stress-induced and a death receptor-mediated pathway, both induce apoptosis via activation of effector caspases, where caspase 3 is generally considered to be the primary executioner of apoptosis [22]. Cleaved caspase 3 antibody detects only large fragment (17/19 kDa) of activated caspase 3 ; thus, the immunopositivity could clearly specifically distinguish cells in apoptosis (cells showing typical apoptotic morphology, outside the areas of necrosis) from normal cells [45]. Active caspase 3 has been found to be significantly associated with unfavorable histological parameters such as high grade and advanced stage of bladder tumours [40]. In a study that included 112 patients with TCC of upper urinary tract, altered expression of caspase 3 was significantly associated with pathologic grade and tumor stage [36]. In this investigation, cleaved caspase 3 immunoreactivity was also significantly associated with tumor differentiation. Previously, it was found that absence of caspase 3 activation was related to the expression of antiapoptotic proteins (Bcl-2, IAP) [46]. Interestingly, the results of linear regression analysis demonstrated significant association of caspase 3 index and $\mathrm{Bcl}-2$ expression in investigated tumors. Proteolytic activation of caspase 3 may be blocked by the overexpression of Bcl-2, but caspase 3 is able to reverse the function of Bcl-2 by cleaving it to a truncated, proapoptotic form [19]. This may at least partially contribute to 
explanation of our findings. Although cleaved caspase 3 index had higher value in UTUC arising in BEN regions than in control tumors, this difference was not statistically significant.

Failure to enter apoptosis allows transformed cells to continue further cell divisions and acquire further mutations [46]. In a hypoxic environment that does not support cell Survival, apoptosis is also involved in selective growth and progression of the least demanding subclones with higher malignant potential. Present investigation has revealed that immunoreactivity of proapoptotic protein Bax is less frequently altered in UTUC arising in endemic regions than in control tumors. However, the difference in cleaved caspase 3 activity between the investigated groups was not statistically significant. This might imply that decreased expression of Bax in BEN tumors compared to control tumors does not necessarily result in the decrease of effective apoptosis.

In conclusion, this investigation of multiple apoptosis-related markers identifies Bax as specific indicator of BEN-associated UTUC. Our findings suggest that decreased proapoptotic activity of Bax together with higher Survivin expression may indicate specific disturbances of intrinsic apoptotic pathway in UTUC arising in endemic areas.

The major limitation of this study is a relatively small number of BEN tumors; however, this is a rare disease, especially in the last ten years.

\section{CONFLICT OF INTERESTS}

The authors declare they have no conflict of interests.

\section{ACKNOWLEDGMENT}

This work was supported by Grant no. 175092 from the Ministry of Education and Science of Serbia.

\section{REFERENCES}

[1] M. Polenakovic and V. Stefanovic, "Balkan nephropathy.," in Oxford Textbook of Clinical Nephrology, J. S. Cameron, A. M. Davison, J. P. Grunfeld, D. Kerr, and E. Ritz, Eds., pp. 857-866, Oxford University Press, Oxford, UK, 1992.

[2] V. Stefanović and M. Polenaković, "Fifty years of research in balkan endemic nephropathy: where are we now?" Nephron, vol. 112, no. 2, pp. c51-c55, 2009.

[3] D. Toncheva, T. Dimitrov, and S. Stojanova, "Etiology of Balkan endemic nephropathy: a multifactorial disease?" European Journal of Epidemiology, vol. 14, no. 4, pp. 389-394, 1998.

[4] V. Stefanovic, D. Toncheva, S. Atanasova, and M. Polenakovic, "Etiology of balkan endemic nephropathy and associated urothelial cancer," American Journal of Nephrology, vol. 26, no. 1, pp. 1-11, 2006.

[5] M. Ivić, "Etiology of endemic nephropathy," Lijecnicki Vjesnik, vol. 91, no. 12, pp. 1273-1281, 1969.

[6] J. P. Cosyns, M. Jadoul, J. P. Squifflet, J. F. De Plaen, D. Ferluga, and C. Van Ypersele De Strihou, "Chinese herbs nephropathy: a clue to Balkan endemic nephropathy?" Kidney International, vol. 45, no. 6, pp. 1680-1688, 1994.

[7] T. Petkova-Bocharova and M. Castegnaro, "Ochratoxin A contamination of cereals in an area of high incidence of Balkan endemic nephropathy in Bulgaria," Food Additives and Contaminants, vol. 2, no. 4, pp. 267-270, 1985.

[8] G. L. Feder, Z. Radovanovic, and R. B. Finkelman, "Relationship between weathered coal deposits and the etiology of Balkan endemic nephropathy," Kidney International Supplements, vol. 40, no. 34, pp. S-9-S-11, 1991.

[9] S. D. Petkovic, "Epidemiology and treatment of renal pelvic and ureteral tumors," Journal of Urology, vol. 114, no. 6, pp. 856-865, 1975.

[10] V. Stefanovic and Z. Radovanovic, "Balkan endemic nephropathy and associated urothelial cancer," Nature Clinical Practice Urology, vol. 5, no. 2, pp. 105-112, 2008. 
[11] M. E. Krasteva and E. I. Georgieva, "Germline p53 single-base changes associated with Balkan endemic nephropathy," Biochemical and Biophysical Research Communications, vol. 342, no. 2, pp. 562-567, 2006.

[12] A. P. Grollman, S. Shibutani, M. Moriya et al., "Aristolochic acid and the etiology of endemic (Balkan) nephropathy," Proceedings of the National Academy of Sciences of the United States of America, vol. 104, no. 29, pp. 12129-12134, 2007.

[13] L. J. Velickovic, T. Hattori, and V. Stefanovic, "Molecular markers in upper urothelial carcinoma associated to Balkan endemic nephropathy. Aristolochic acid as the major risk factor of the worldwide disease," TheScientificWorldJournal, vol. 9, pp. 1360-1373, 2009.

[14] J. J. McKnight, S. B. Gray, H. F. O'Kane, S. R. Johnston, and K. E. Williamson, “Apoptosis and chemotherapy for bladder cancer," Journal of Urology, vol. 173, no. 3, pp. 683-690, 2005.

[15] J. A. Karam, Y. Lotan, P. I. Karakiewicz et al., "Use of combined apoptosis biomarkers for prediction of bladder cancer recurrence and mortality after radical cystectomy," Lancet Oncology, vol. 8, no. 2, pp. 128-136, 2007.

[16] A. Lopez-Beltran, G. Sauter, and T. Gasser, "Tumors of the urinary system. Infiltrating urothelial carcinoma," in World Health Organization Classification of Tumours. Pathology and Genetics. Tumours of the Urinary System and Male Genital Organs, J. N. Eble, G. Sauter, J. I. Epstein, and I. A. Sesterhenn, Eds., pp. 93-109, IARC, Lyon, France, 2004.

[17] L. H. Sobin and C. Wittekind, Eds., TNM Classification of Malignant Tumors, John Wiley \& Son, New York, NY, USA, 6th edition, 2002.

[18] E. M. Genega, M. Kapali, M. Torres-Quinones et al., "Impact of the 1998 World Health Organization/International Society of Urological Pathology classification system for urothelial neoplasms of the kidney," Modern Pathology, vol. 18, no. 1, pp. 11-18, 2005.

[19] I. Giannopoulou, L. Nakopoulou, A. Zervas et al., "Immunohistochemical study of pro-apoptotic factors Bax, Fas and CPP32 in urinary bladder cancer: prognostic implications," Urological Research, vol. 30, no. 5, pp. 342-345, 2002.

[20] W. Yin, N. Chen, Y. Zhang et al., "Survivin nuclear labeling index: a superior biomarker in superficial urothelial carcinoma of human urinary bladder," Modern Pathology, vol. 19, no. 11, pp. 1487-1497, 2006.

[21] R. P. Singh, A. Tyagi, G. Sharma, S. Mohan, and R. Agarwal, "Oral silibinin inhibits in vivo human bladder tumor xenograft growth involving down-regulation of survivin," Clinical Cancer Research, vol. 14, no. 1, pp. 300-308, 2008.

[22] A. Bressenot, S. Marchal, L. Bezdetnaya, J. Garrier, F. Guillemin, and F. Plénat, "Assessment of apoptosis by immunohistochemistry to active caspase-3, active caspase-7, or cleaved PARP in monolayer cells and spheroid and subcutaneous xenografts of human carcinoma," Journal of Histochemistry and Cytochemistry, vol. 57, no. 4, pp. 289-300, 2009.

[23] P. Colin, P. Koenig, A. Ouzzane et al., "Environmental factors involved in carcinogenesis of urothelial cell carcinomas of the upper urinary tract," BJU International, vol. 104, no. 10, pp. 1436-1440, 2009.

[24] J. W. F. Catto, D. R. Yates, I. Rehman et al., "Behavior of urothelial carcinoma with respect to anatomical location," Journal of Urology, vol. 177, no. 5, pp. 1715-1720, 2007.

[25] S. Eltz, E. Comperat, O. Cussenot, and M. Rouprêt, "Molecular and histological markers in urothelial carcinomas of the upper urinary tract," BJU International, vol. 102, no. 5, pp. 532-535, 2008.

[26] F. D. Debelle, J. L. Vanherweghem, and J. L. Nortier, "Aristolochic acid nephropathy: a worldwide problem," Kidney International, vol. 74, no. 2, pp. 158-169, 2008.

[27] V. Stefanovic, R. Cukuranovic, S. Miljkovic, D. Marinkovic, and D. Toncheva, "Fifty years of balkan endemic nephropathy: challenges of study using epidemiological method," Renal Failure, vol. 31, no. 5, pp. 409-418, 2009.

[28] L. Jankovic Velickovic, T. Hattori, Z. Dolicanin et al., "Upper urothelial carcinoma in Balkan endemic nephropathy and non-endemic regions: a comparative study of pathological features," Pathology Research and Practice, vol. 205, no. 2, pp. 89-96, 2009.

[29] L. J. Velickovic, T. Hattori, M. Visnjic, I. Dimov, M. Stojanovic, and V. Stefanovic, "E-cadherin expression in upper urothelial carcinoma in Balkan Endemic Nephropathy and non-endemic regions," Pathology Research and Practice, vol. 205, no. 10, pp. 682-689, 2009. 
[30] N. Nouraee, S. J. Mowla, A. Ozhand, M. Parvin, S. A. M. Ziaee, and N. Hatefi, "Expression of survivin and its spliced variants in bladder tumors as a potential prognostic marker," Urology Journal, vol. 6, no. 2, pp. 101-108, 2009.

[31] K. Tanaka, S. Iwamoto, G. Gon, T. Nohara, M. Iwamoto, and N. Tanigawa, "Expression of survivin and its relationship to loss of apoptosis in breast carcinomas," Clinical Cancer Research, vol. 6, no. 1, pp. 127-134, 2000.

[32] O. Moussa, H. Abol-Enein, N. K. Bissada, T. Keane, M. A. Ghoneim, and D. K. Watson, "Evaluation of survivin reverse transcriptase-polymerase chain reaction for noninvasive detection of bladder cancer," Journal of Urology, vol. 175, no. 6, pp. 2312-2316, 2006.

[33] A. C. Fields, G. Cotsonis, D. Sexton, R. Santoianni, and C. Cohen, "Survivin expression in hepatocellular carcinoma: correlation with proliferation, prognostic parameters, and outcome," Modern Pathology, vol. 17, no. 11, pp. 1378-1385, 2004.

[34] S. F. Shariat, R. Ashfaq, P. I. Karakiewicz, O. Saeedi, A. I. Sagalowsky, and Y. Lotan, "Survivin expression is associated with bladder cancer presence, stage, progression, and mortality," Cancer, vol. 109, no. 6, pp. 11061113, 2007.

[35] L. Skagias, E. Politi, A. Karameris et al., "Survivin expression as a strong indicator of recurrence in urothelial bladder cancer. Predictive value of nuclear versus cytoplasmic staining," Anticancer Research, vol. 29, no. 10, pp. 4163-4167, 2009.

[36] I. G. Jeong, S. H. Kim, H. G. Jeon et al., "Prognostic value of apoptosis-related markers in urothelial cancer of the upper urinary tract," Human Pathology, vol. 40, no. 5, pp. 668-677, 2009.

[37] K. Nakanishi, S. Tominaga, S. Hiroi et al., "Expression of survivin does not predict survival in patients with transitional cell carcinoma of the upper urinary tract," Virchows Archiv, vol. 441, no. 6, pp. 559-563, 2002.

[38] Y. B. Chen, J. J. Tu, J. Kao, X. K. Zhou, and Y. T. Chen, "Survivin as a useful adjunct marker for the grading of papillary urothelial carcinoma," Archives of Pathology and Laboratory Medicine, vol. 132, no. 2, pp. 224-231, 2008.

[39] H. S. Kadhim, A. S. Abdulamir, R. R. Hafidh, F. Abubaker, and K. A. Abbas, "Investigations in the molecular events of transitional cell carcinoma of the bladder," American Journal of Biochemistry and Biotechnology, vol. 4, no. 4, pp. 408-415, 2008.

[40] E. Karamitopoulou, C. A. Rentsch, R. Markwalder, C. Vallan, G. N. Thalmann, and T. Brunner, "Prognostic significance of apoptotic cell death in bladder cancer: a tissue microarray study on 179 urothelial carcinomas from cystectomy specimens," Pathology, vol. 42, no. 1, pp. 37-42, 2010.

[41] K. Nakanishi, S. Tominaga, T. Kawai, C. Torikata, T. Aurues, and T. Ikeda, "Expression of bcl-2 oncoprotein in transitional cell carcinoma of the upper urinary tract," Virchows Archiv, vol. 432, no. 5, pp. 445-450, 1998.

[42] J. C. Reed, "Proapoptotic multidomain Bcl-2/Bax-family proteins: mechanisms, physiological roles, and therapeutic opportunities," Cell Death and Differentiation, vol. 13, no. 8, pp. 1378-1386, 2006.

[43] J. F. Curtin and T. G. Cotter, "Live and let die: regulatory mechanisms in Fas-mediated apoptosis," Cellular Signalling, vol. 15, no. 11, pp. 983-992, 2003.

[44] K. Yamana, V. Bilim, N. Hara et al., "Prognostic impact of FAS/CD95/APO-1 in urothelial cancers: decreased expression of Fas is associated with disease progression," British Journal of Cancer, vol. 93, no. 5, pp. 544-551, 2005.

[45] A. M. Gown and M. C. Willingham, "Improved detection of apoptotic cells in archival paraffin sections: immunohistochemistry using antibodies to cleaved caspase 3," Journal of Histochemistry and Cytochemistry, vol. 50, no. 4, pp. 449-454, 2002.

[46] J. J. Oudejans, A. Harijadi, S. A. G. M. Cillessen et al., "Absence of caspase 3 activation in neoplastic cells of nasopharyngeal carcinoma biopsies predicts rapid fatal outcome," Modern Pathology, vol. 18, no. 7, pp. 877-885, 2005. 
This article should be cited as follows:

Ljubinka Jankovic-Velickovic, Slavica Stojnev, Ana Ristic-Petrovic, Zana Dolicanin, Takanori Hattori, Kenichi Mukaisho, Mariola Stojanovic, and Vladisav Stefanovic, "Pro- and Antiapoptotic Markers in Upper Tract Urothelial Carcinoma Associated with Balkan Endemic Nephropathy," TheScientificWorldJOURNAL, vol. 11, pp. 1699-1711, 2011. 


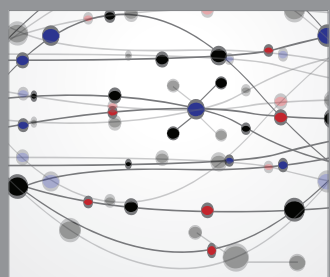

The Scientific World Journal
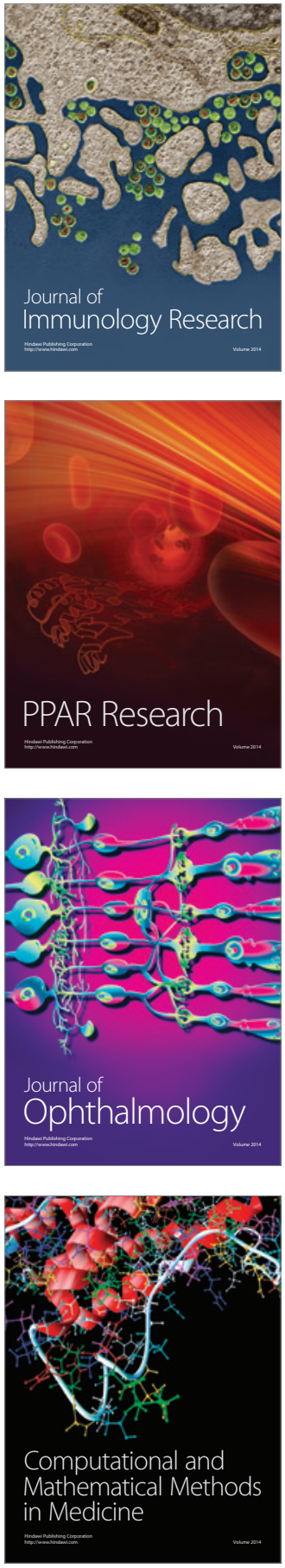



Gastroenterology

Research and Practice
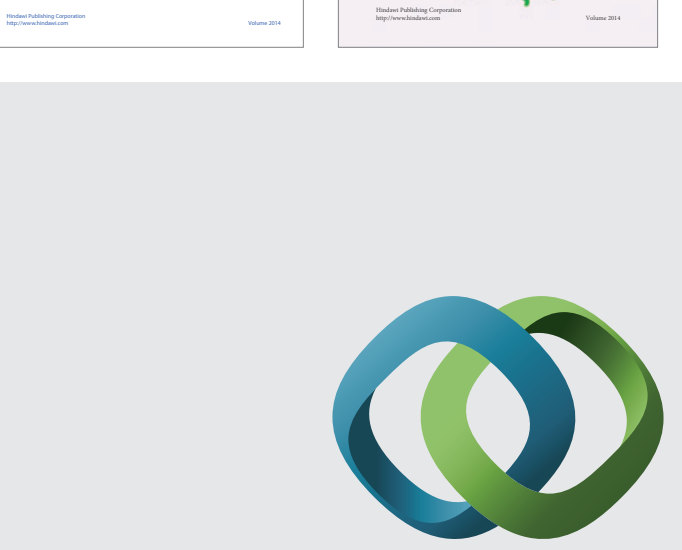

\section{Hindawi}

Submit your manuscripts at

http://www.hindawi.com
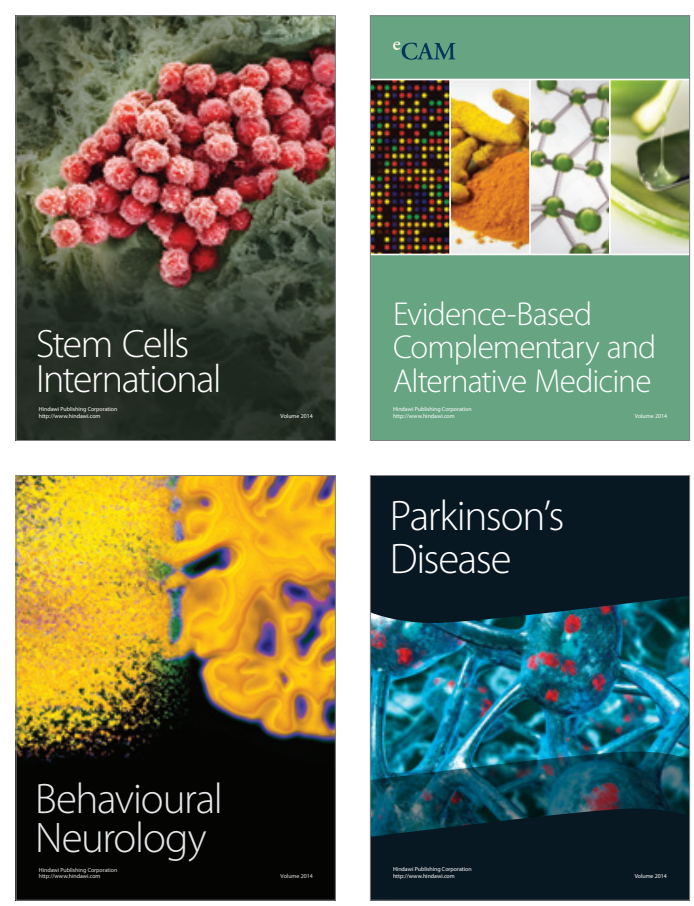

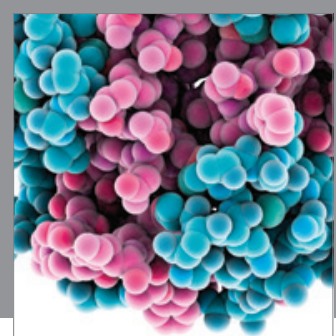

Journal of
Diabetes Research



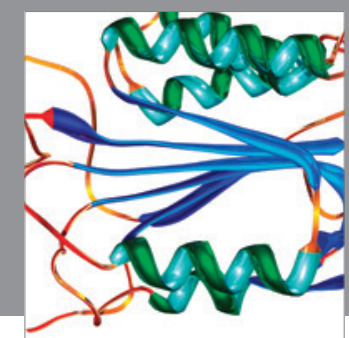

Disease Markers
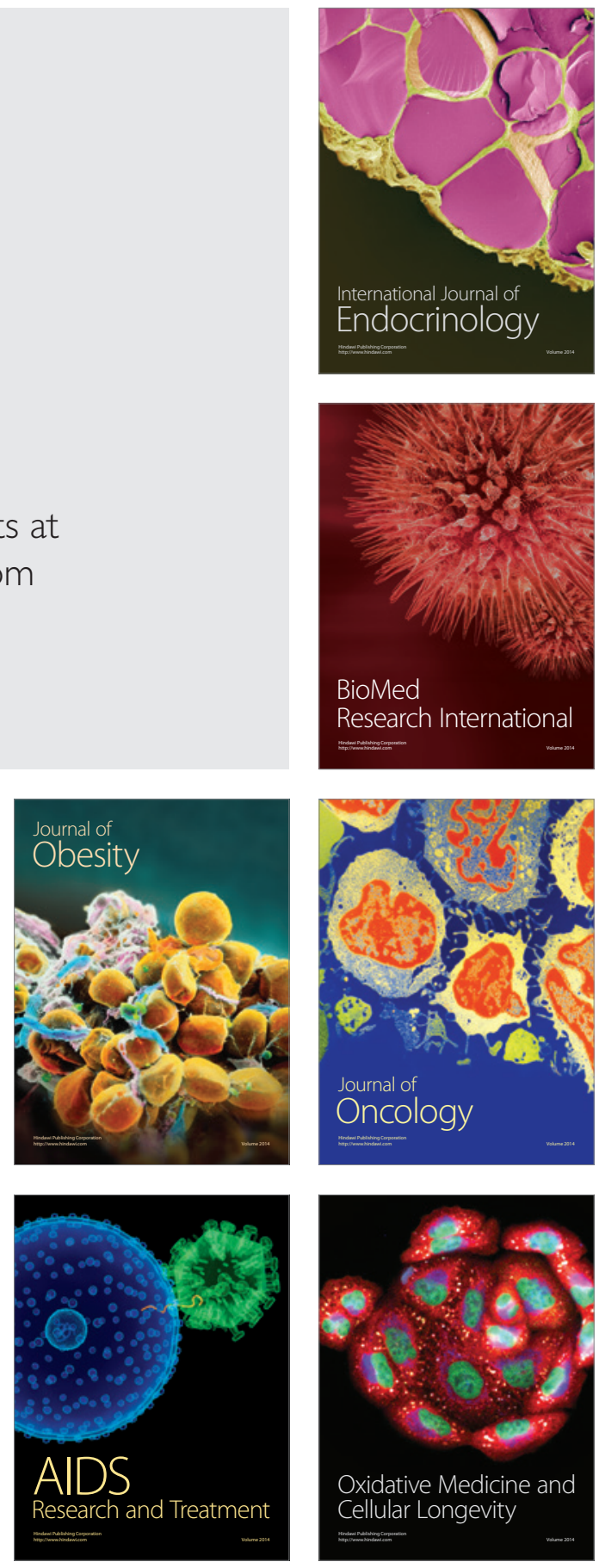